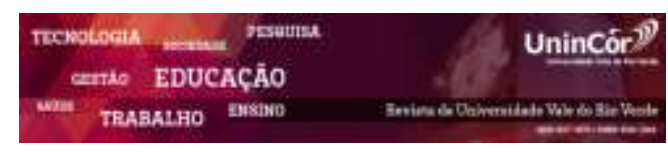

Revista da Universidade Vale do Rio Verde ISSN: 1517-0276 / EISSN: 2236-5362 v. $17 \mid$ n.1 | Ano 2019

Gustavo Cunha de Araújo

Universidade Federal do Tocantins gustavocaraujo@yahoo.com.br

Helena Quirino Porto Aires Universidade Federal do Tocantins hequirino.uft@mail.uft.edu.br

\section{O ESTÁGIO EM ARTE NAS ESCOLAS \\ DO CAMPO: UM ESTUDO DE CASO NA \\ LICENCIATURA EM EDUCAÇÃO DO \\ CAMPO COM HABILITAÇÃ O EM \\ ARTES E MÚSICA EM TOCANTINS}

\section{RESUMO}

$\mathrm{O}$ artigo analisa uma experiência pedagógica realizada com estudantes da Licenciatura em Educação do Campo com habilitação em Artes e Música, na Universidade Federal do Tocantins, campus Tocantinópolis, Brasil, acerca do Estágio Curricular Supervisionado na disciplina de Arte em escolas do campo. De abordagem qualitativa e de caráter exploratório, este estudo de caso teve como instrumentos de coletas de dados as entrevistas semiestruturadas realizadas com discentes do referido curso, além da pesquisa empírica e análise documental. A forma de análise dos dados seguiu a perspectiva da técnica da pesquisa interpretativa. Os resultados demonstraram que o estágio curricular supervisionado na Educação do Campo possibilita aos estudantes produzir conhecimento acerca da prática docente no contexto camponês, bem como das formas de viver e trabalhar no campo, que envolve tanto os aspectos sociais e políticos, quanto os econômicos e culturais. É necessário e urgente formar professores que preenchem a lacuna de docentes que atuam no meio rural no Estado do Tocantins, para que seja possível atender efetivamente a demanda da Educação Básica nesse Estado, principalmente, na disciplina de Arte, tão carente de professores com formação nessa área em áreas rurais.

Palavras-chave: Estágio Curricular Supervisionado. Licenciatura em Educação do Campo. Formação de Professores. Arte.

\section{THE STAGE IN ART IN THE RURAL SCHOOLS: A CASE STUDY IN RURAL EDUCATION WITH ENABLING IN ARTS AND MUSIC IN TOCANTINS}


teachers who work in rural areas in the State of Tocantins, so that it is possible to effectively meet the demand for Basic Education in that State, especially in the Art discipline, so lacking in teachers with area in rural areas.

Keywords: Supervised Internship. Degree in Rural Education. Teacher Training. Art.

\section{Recebido em: 20/12/2018 - Aprovado em: 10/04/2019 - Disponibilizado em: 15/07/2019}

\section{INTRODUÇÃO}

Um desafio crucial para quem faz uma licenciatura hoje no Brasil é o estágio curricular supervisionado. Por ser a oportunidade de o estudante compreender melhor a docência, em seu aspecto teórico e prático, é um momento no qual ele vai articular o conhecimento desenvolvido em sala de aula com a prática de "ser professor", ao considerar nesse processo a possibilidade de vivenciar aspectos importantes para a profissão, como metodologias, técnicas de ensino, avaliações, interações professor-aluno entre outros.

Nessa perspectiva, o estágio nas licenciaturas é uma rica oportunidade de formação inicial para estudantes compreenderem a complexidade e especificidades das práticas pedagógicas e institucionais, bem como as ações desenvolvidas por professores no âmbito educacional (PIMENTA, 2010). É importante assinalar que ainda é incipiente na literatura científica brasileira estudos sobre o estágio em escolas do campo, o que reforça a relevância desta pesquisa para o debate educacional.

A partir dessas considerações iniciais, esta pesquisa tem como objetivo principal analisar uma experiência pedagógica realizada com estudantes da Licenciatura em Educação do Campo com habilitação em Artes e Música, na
Universidade Federal do Tocantins, campus Tocantinópolis, acerca do estágio em escolas do campo. Ao considerar que o curso formou sua primeira turma este ano, é importante fazer um primeiro diagnóstico acerca da realização do estágio curricular supervisionado realizado nas escolas rurais, com o objetivo de levantar possíveis questionamentos e melhorias para a execução do estágio nessa licenciatura e, consequentemente, sua efetivação nas escolas de Educação Básica.

$\mathrm{Na}$ primeira seção apresentamos um breve panorama histórico e pedagógico da licenciatura em Educação do Campo no Brasil e em Tocantins, com o objetivo de contextualizar o objeto desta investigação. Em seguida, apresentamos os procedimentos metodológicos utilizados e, na sequência, os dados coletados e analisados à luz da literatura científica que fundamentou este estudo. Por fim, são socializadas as conclusões desta pesquisa.

\section{PROCEDIMENTOS METODOLÓGICOS}

Por se tratar de uma pesquisa de abordagem qualitativa na educação, ressaltamos alguns aspectos importantes, lembrado por Bogdan e Biklen (1994) que entendemos serem pertinentes neste trabalho: o contexto cultural do ambiente o qual será investigado e terá os dados 
coletados e interpretados é importante para a pesquisa educacional; a pesquisa é descritiva, pois, os dados obtidos podem ser escritos ou visuais e descrevem determinada realidade observada; e os significados das ações ocorridas in loco são fundamentais para o desenvolvimento das análises e suas interpretações. Nesse mesma linha de raciocínio, Triviños (1987) corrobora que a maioria dos estudos na educação são descritivos, e sem aporte teórico que fundamenta a pesquisa é impossível entender e analisar as informações coletadas.

Como estratégia metodológica, utilizamos o estudo de caso que, segundo Yin (2003) analisa acontecimentos contemporâneos de determinado fenômeno da realidade, em consonância com dois importantes instrumentos metodológicos: a observação e as entrevistas, assim como fizemos nesta investigação.

Em consonância com essa metodologia, utilizamos a pesquisa interpretativa (ERICKSON, 1985) na forma de análise dos dados que, para o autor, é bastante significativa na pesquisa educacional, por se interessar pelo espaço cultural e social da sala de aula e o ensino e aprendizado ali construído, e pelo significado das ações que acontecem nesse mesmo espaço, promovidas tanto por alunos quanto pelo professor durante o processo educativo.

À luz do pensamento de Erickson (1985), algumas questões são pertinentes no trabalho de campo que foi realizado e que envolve a pesquisa interpretativa, as quais entende-se serem importantes e adequadas neste trabalho. Baseado nesses pressupostos procurou-se levantar algumas questões para esta pesquisa que estão em consonância com o método da pesquisa interpretativa:

a) o que está acontecendo nas ações desenvolvidas no Estágio Curricular Supervisionado?

b) como essas ações envolvem os estudantes do curso de Educação do Campo e professores?

c) onde esses acontecimentos são organizados? Em qual instituição?

d) o que acontece na instituição é diferente do que ocorre em outras instituições?

Para a geração dos dados, utilizamos a entrevista semiestruturada de 18 questões aplicadas a 55 alunos jovens e adultos do curso de Licenciatura em Educação do Campo com habilitação em Artes e Música da Universidade Federal do Tocantins, campus Tocantinópolis, que participaram das 4 disciplinas de estágios curriculares supervisionados do curso, ao longo dos anos de 2016 e 2017. Contudo, devido à extensão desse artigo, socializamos apenas alguns trechos significativos dos depoimentos dos estudantes. É importante ressaltar que durante as entrevistas foi esclarecido a eles pelos pesquisadores os objetivos da pesquisa, os procedimentos metodológicos e demais informações importantes do estudo (SZYMANSKI, 2004), bem como a preservação de suas identidades, com o objetivo de atender a ética em pesquisa com seres humanos.

É importante partir do significado dos indivíduos para com a experiência com o tema estudado; em outras palavras, deve-se escolher pessoas que de alguma forma participaram, viveram e experenciaram com as situações do tema da pesquisa, para que possam contribuir 
com relatos significativos para a pesquisa em questão.

Sobre a importância da entrevista em uma pesquisa, Thompson (1998, p. 146-147), enfatiza que a mesma "[...] é muito mais fidedigno e preciso de um encontro do que um registro simplesmente escrito. Uma vez que todas as palavras estão ali exatamente como foram faladas e, característica este que mostra caminhos e nuances da incerteza, bem como de fatores sociais". A respeito da transcrição de entrevistas, Gomes, Vizolli, Santos e Stephani (2016, p. 376) asseveram que:

A transcrição é um processo de gravação da entrevista, que é um registro literal desta e transforma objetos auditivos em visuais. Após a gravação, passamos para a textualização, um processo mais analítico, onde buscamos interpretar o que foi dito pelos entrevistados e construir um texto a partir de reordenações e reorganização de ideias apresentadas nos diferentes momentos da entrevista, reproduzindo as falas de forma fidedigna.

Outro instrumento metodológico para a geração de dados neste estudo foi a observação direta das aulas de estágio curricular supervisionado durante 2 anos no referido curso, que nos possibilitou elaborar reflexões e produzir análises dessas informações na pesquisa de campo (VIANNA, 2003).

Assim, é possível afirmar que a pesquisa apresentou características bastante favoráveis, com elementos teóricos que fundamentaram a argumentação e reflexões construídas neste estudo.

\section{RESULTADOS E DISCUSSÕES}

De acordo com Molina (2015) atualmente há no Brasil 42 cursos de
Licenciatura em Educação do Campo ofertados em instituições públicas de ensino superior. Iniciaram em 2006, a partir de um projeto piloto em 4 universidades, a saber: Universidade Federal de Minas Gerais, Universidade de Brasília, Universidade Federal da Bahia e Universidade Federal de Sergipe. Contudo, para que esses cursos fossem ampliados no país, o PROCAMPO (Programa de Apoio à Formação Superior em Educação do Campo), por meio do Edital de Seleção $n^{\circ}$ 02/2012SESU/SETEC/SECADI/MEC-2012, deu continuidade na criação de novos cursos, como os localizados na Universidade Federal do Tocantins, nos campi de Arraias e Tocantinópolis, respectivamente.

É importante destacar que os cursos de Educação do Campo funcionam por meio da Pedagogia da Alternância, em que o processo de ensino e aprendizagem acontece nos Tempo Universidade (TU) - quando os estudantes estão na universidade cursando as disciplinas do curso - e Tempo Comunidade (TC), quando os alunos voltam para as suas comunidades onde residem, para desenvolver as atividades e pesquisas propostas pelos professores durante o TU. Ademais, a justificativa por ofertar por meio dessa área do conhecimento (Artes) é devido à carência significativa de professores de Artes em Tocantins, principalmente, nas escolas de Educação Básica localizadas no meio rural.

No que se refere ao curso de Licenciatura em Educação do Campo com habilitação em Artes e Música da Universidade Federal do Tocantins, campus Tocantinópolis, o Projeto Pedagógico do Curso (PPC) abrange as seguintes áreas de atuação: 
A) Docência na Educação Fundamental, nos anos finais do Ensino Fundamental e no Ensino Médio na modalidade Normal, na Educação de Jovens e Adultos, assim como em Educação Profissional, na área de serviços e apoio escolar, além de em outras áreas nas quais conhecimentos adquiridos de forma multidisciplinar em uma área de conhecimento prevista, especialmente nas escolas do campo; B) Gestão educacional, entendida numa perspectiva democrática, que integre as diversas atuações e funções do trabalho pedagógico e de processos educativos escolares e não escolares, especialmente no que se refere ao planejamento, à administração, à coordenação, ao acompanhamento, à avaliação de planos e de projetos pedagógicos, bem como análise, formulação, implementação, acompanhamento e avaliação de políticas públicas e institucionais na área de educação do campo e escolas rurais/do campo; C) Produção e difusão do conhecimento científico e tecnológico do campo educacional, em contextos escolares e não-escolares. Atuar, em espaços escolares e não escolares, na promoção da aprendizagem de sujeitos do campo em diferentes fases do desenvolvimento humano, em diversos níveis e modalidades do processo educativo. (PROJETO PEDAGÓGICO DO CURSO, 2018, p. 82).

É importante ressaltar que nas Diretrizes de Estágio Supervisionado do referido curso e, segundo a Resolução n. 003/2005 do Conselho de Ensino Pesquisa e Extensão - CONSEPE da UFT, o Estágio será:

[...] supervisionado e orientado, em cumprimento ao dispositivo da Lei 11.788/08, por um Coordenador de Estágio, um Professor Orientador e um Professor Supervisor Externo à UFT, que acompanhará passo a passo os acadêmicos na escola campo. (PROJETO PEDAGÓGICO DO CURSO, 2018, p. 108).

Nessa linha de pensamento, Pimenta (2010) assevera que os estágios nos cursos de licenciatura são, em sua maioria, trabalhados de forma desconexa com a realidade das escolas públicas de Educação Básica no Brasil, inclusive, nas localizadas em áreas rurais que, geralmente, são bem precárias tanto em sua infraestrutura quanto no ensino ofertados nesses lugares, que envolvem carência de materiais didáticos, falta de água potável entre outros fatores que se tornam grandes obstáculos aos docentes e alunos.

A esse respeito, Pimenta (2010) faz uma interessante observação: toda profissão, independente da área, é prática e técnica. A primeira, no sentido de realizar uma atividade qualquer (assim como o professor e alunos fazem no contexto escolar). Técnica, pois, para o desenvolvimento dessas atividades, são necessários métodos e instrumentos. Nesse sentido, na articulação entre prática e técnica no bojo educacional, os alunos podem, sob orientação de um professor, elaborar seus próprios métodos para trabalhar durante o desenvolvimento do estágio.

É importante assinalar que para realização do planejamento acerca do estágio curricular supervisionado, o Colegiado do curso de Educação do Campo nomeou uma equipe de professores responsáveis para a articulação e organização da realização do Estágio. Essas informações coadunam com o que está explicitado no Projeto Pedagógico do curso de Educação do Campo/campus Tocantinópolis/UFT, e das Diretrizes de Estágio da própria Universidade Federal do Tocantins (UFT).

Após essa breve explanação teórica para contextualizamos a pesquisa, apresentamos a seguir alguns relatos descritos e analisados de trechos das entrevistas semiestruturadas realizadas com os educandos jovens e adultos da 
Educação do Campo da UFT/Tocantinópolis, participantes dos 4 estágio curriculares supervisionados ao longo do curso. Assim, a respeito da experiência de estagiar nas escolas do campo, os estudantes se posicionaram:

\begin{abstract}
Entrevistado $A^{l}$ (2017):
"uma experiência muito boa é a oportunidade que temos para observar a metodologia dos professores, de analisar tudo que acontece dentro da sala de aula e de expor tudo que aprendi na faculdade no decorrer do curso de Educação do Campo".
\end{abstract}

\section{Entrevistado I (2017):}

"a experiência de estagiar na escola foi desafiadora, pois enquanto estudávamos na Universidade durante quatro horas uma mesma disciplina, na escola básica tivemos que planejar um trabalho que fosse significativo, ao mesmo tempo em que deveria ser desenvolvida em aulas de no máximo quarenta e oito minutos."

Os relatos dos alunos permitem afirmar que o estágio é mais que um desafio: é uma oportunidade significativa para colocarem em práticas os conceitos e teorias aprendidas e construídas ao longo das aulas do Tempo Universidade na UFT/Tocantinópolis, Ademais, conseguiram, também, relacionar essas duas dimensões (teoria e prática) durante a suas práticas pedagógicas desenvolvidas nas escolas pesquisadas, o que é importante para que possam compreender a docência e como essa profissão se constitui hoje em dias na Educação Básica.

Sobre o envolvimento da universidade e escolas frente à realização do Estágio Curricular Supervisionado, assim se posicionaram:

Estudante A (2017):

Por parte da universidade deve haver mais organização e informação para os discentes poderem realizar o estágio com sucesso.

\footnotetext{
${ }^{1}$ Os estudantes foram designados por códigos, para preservar o seu anonimato e atender os princípios éticos da pesquisa científica com seres humanos.
}

Já por parte da escola que estagiei os professores devem acompanhar melhor os estagiários e não deixar tudo por conta da gente, mas a equipe pedagógica me recebeu muito bem.

\section{Estudante F (2017):}

No meu ponto de vista falta mais diálogo entre universidade e escola, porém, percebe-se que existe uma necessidade de comunicação e de um acompanhamento mais de perto tanto por parte da universidade quanto por parte da escola.

Nas palavras dos entrevistados sobre a participação da escola e da universidade na realização do estágio curricular supervisionado, constatamos que há necessidade de ambas as instituições trabalharem em parceria com os envolvidos durante o processo de formação do professor, uma vez que a realização do estágio requer a organicidade de muitas questões burocráticas para que de fato se efetive na prática, como, por exemplo, o auxílio no preenchimento de documentos para efetivar o estágio.

Sobre as sugestões para melhorar o estágio nas escolas, os estudantes foram unânimes quando responderam que é preciso ter mais acompanhamento por parte dos professores orientadores na realização do estágio, o que pode ser observado na sequência:

\section{Estudante A (2017):}

"Que os professores da educação do campo pudessem acompanhar mais os discentes no estágio, e também ajudarem os alunos a confeccionar o material pedagógico para realizar as aulas, pois os professores das escolas apenas dão o tema $e$, para a gente que mora no campo, muitas vezes não tem internet para pesquisar, nem biblioteca, e no livro didático quase não o encontra, com isso dificulta o nosso trabalho."

Estudante D (2017):

"Resolvendo os problemas burocráticos das fichas que atrapalham muito nosso estágio, ou seja, que a universidade faça um treinamento com os alunos iniciantes no estágio para não dar tanto trabalho." 
Estudante I (2017):

"Começaria pelo preenchimento de cada ficha mostrando no datashow para os alunos se apropriarem desse detalhe muito importante do estágio, não importando se iria levar o tempo de uma aula de quatro horas, o tempo suficiente para a realização da prática do estágio, o que deve ser planejado na hora da elaboração do calendário."

Em seus relatos, fica claro que a burocracia do preenchimento dos inúmeros formulários para iniciarem o estágio e um acompanhamento maior por parte dos docentes dessa disciplina se mostram significativos para que esse processo ocorra da melhor forma possível. Contudo, é importante ressaltar que a ausência dos professores em alguns momentos de acompanhamento no estágio se deve ao fato de a universidade (UFT) ter os seus recursos financeiros reduzidos, devido muito ao corte de investimentos nas universidades públicas nos últimos anos feito pelo governo federal, o que implica no desenvolvimento pleno das atividades acadêmicas. Neste caso específico, a universidade teve dificuldades em pagar combustível para levar alunos e professores em todas as comunidades de Tocantins cadastradas para a realização do estágio curricular para que os docentes pudessem acompanhá-los. Assim, é importante ressaltar que,

O Estágio Supervisionado no Curso de Licenciatura em Educação do Campo deve possibilitar aos acadêmicos a formação e a construção de conhecimentos necessários à sua formação, ou seja, para o trabalho com as escolas do campo e no campo. Aquelas situadas na sede do município, mas que recebem boa parte de seus alunos do meio rural e estas que se situam no meio rural propriamente dito (PROJETO PEDAGÓGICO DO CURSO, 2018, p. 107).
Sobre a questão: de que forma você pensa que deveria acontecer o estágio na prática? Os entrevistados responderam que:

Estudante A (2017):

"O estágio deveria ocorrer de forma mais simples sem precisar tanto burocracia."

Estudante C (2017):

"Em primeiro lugar a questão dos documentos para o estágio, a partir do momento que saímos para nossas comunidades, todas as fichas deveriam ser preenchidas juntamente com o pessoal da Central de Estágio, pois na volta sempre tem uma ficha que não está certa, ou pelas datas, ou por qualquer outra coisa que seja."

Estudante F (2017):

"De forma mais objetiva menos regras $e$ mais ação, de forma que o sujeito estagiário possa ter mais oportunidades e reconhecimento dentro das escolas, de forma que de acordo com a grade curricular da escola, o estagiário possa expressar e transmitir seu conhecimento adquirido no decorrer do curso."

Novamente, para os alunos, o estágio curricular supervisionado deveria ser menos burocrático e que a central de estágio auxiliasse os discentes nos preenchimentos das fichas com mais praticidade, tendo em vista as dúvidas que surgem no decorrer do preenchimento dela, em que muitas das vezes se leva muito tempo para concretizá-las. Nessa linha de pensamento,

O estágio traduz as características do Projeto Pedagógico do curso, de seus objetivos, interesses e preocupações formativas, e traz a marca do tempo histórico e das tendências pedagógicas adotadas pelo grupo de docentes formadores e das relações organizacionais do espaço acadêmico a que está vinculado. Traz ainda a marca do(s) professor (ES) que orienta $(\mathrm{m})$, dos conceitos e práticas por ele(s) adotados (PIMENTA, 2010, p. 113).

Em seguida, foi perguntado aos estudantes como foi a experiência de estagiar na disciplina de Arte. Assim foram os seus relatos: 


\section{Estudante A (2017):}

Minha experiência com estágio na disciplina de Arte, às vezes me deixou com muita decepção, pois arte na escola não é considerada uma disciplina, todos os alunos a considera como uma atividade simples, que não precisa de atenção, e que os conteúdos repassados para o campo não têm nada com a realidade dos alunos presentes nesse espaço.

Estudante H (2017):

Pra mim, foi algo bom. Me deparar com o desafio de lecionar uma disciplina que sofreu grandes transformações e que ainda enfrenta inúmeros desafios é sempre instigante. Resolvi fazer o melhor que pude e, com as ferramentas certas e disponíveis busquei dar um novo olhar para a arte nas minhas aulas de estágio.

\section{Estudante B (2017):}

Bem, não teria palavra melhor para descrever: um desafio. No primeiro momento coloco a situação de que Arte ainda não é tão valorizada (em observação tanto por quem ministra e por quem aprende) e ainda há uma ressalva: quem ministra a disciplina não é um profissional formado exatamente em artes, e sim, em pedagogia, letras, história, etc.

Os seus relatos deixam claro dois importantes fatores: a) a disciplina de Arte ainda não é considerada como uma disciplina importante e valorizada no currículo escolar, em comparação com as demais do currículo; b) A maioria dos professores que lecionam nessa disciplina não são formados na área de artes (artes visuais, teatro, dança e música), o que confirma a carência de cursos de formação inicial e continuada no estado do Tocantins, uma vez que nesse estado há apenas um curso específico de artes na UFT de Palmas, o que é insuficiente para atender toda a demanda do estado. Contudo, de forma gera, apesar das dificuldade enfrentadas pelos alunos, é possível afirmar que estagiar nessa disciplina foi importante e significativo para o processo de ensino e aprendizagem deles para com a docência.
Segundo Lopes e Silva (2018), a docência em escolas do campo precisa ser pensada com mais relevância, uma vez que, além de se referir a formação docente para atuar nesse âmbito, deve-se considerar nessa formação a emancipação humana e princípios educativos ligados a luta pela terra e qualidade de ensino desenvolvido nas escolas localizadas no meio rural.

Por fim, ao serem perguntados sobre o significado de ser professor no contexto da educação do campo, os estudantes entrevistados disseram o seguinte:

\section{Estudante B (2017): \\ "Resgatar valores éticos, sociais, culturais através de habilidades e competências desenvolvidas através de conteúdos curriculares garantidos pela $L D B$." \\ Estudante G (2017): \\ "Só o fato de ser professor já é um desafio, e ser do campo significa ser um lutador conquistador, pois, os desafios são maiores."}

Um aspecto importante está presente nas falas dos alunos: atuar nas escolas do campo como docente é mais que um desafio, é ser resistente as intempéries da vida escolar camponesa, é lutar contra um ensino, na maioria das vezes, precário, como falta de estrutura das escolas, nem sempre contando com água potável, falta de materiais didáticos entre tantos outros obstáculos que torna essa profissão docente um grande desafio, mas, que precisa ser superado.

Se o movimento da Educação do Campo compreende que a Escola do Campo deve ser uma aliada dos sujeitos sociais em luta para poderem continuar existindo enquanto camponeses; para continuar garantindo a reprodução material de suas vidas a partir do trabalho na terra, é imprescindível que a formação dos educadores que estão sendo preparados para atuar nestas escolas, considere, antes de tudo, que a existência e 
permanência (tanto destas escolas, quanto deste sujeitos) passa, necessariamente, pelos caminhos que se trilharão a partir dos desdobramentos da luta de classes; do resultado das forças em disputa na construção dos distintos projetos de campo na sociedade brasileira (MOLINA, 2015, p. 146).

Com essas reflexões produzidas, compreendemos que o estágio curricular supervisionado não deve se referir apenas ao cumprimento de créditos acadêmicos no curso de licenciatura, pois é mais que isso: envolve tanto questões relacionadas ao processo de ensino e aprendizagem na prática docente como na articulação de conhecimentos teóricos e práticos que possibilitam ao acadêmico conhecer os desafios e oportunidades de crescimento pessoal e profissional para a área da qual está se formando.

\section{CONSIDERAÇÕES FINAIS}

Constatamos neste estudo desenvolvido que o estágio curricular supervisionado na Educação do Campo possibilita aos estudantes produzir conhecimento acerca das formas de viver e trabalhar no campo, que envolve tanto os aspectos sociais e políticos, quanto os econômicos e culturais, presentes em seu contexto.

Além de ser uma relevante oportunidade de vivenciar os aspectos teóricos e práticos da docência e, pelo fato do curso ter surgido a partir da luta de movimentos sociais para atender a população camponesa, é necessário e urgente formar professores que preenchem a lacuna de docentes que atuam no meio rural, para que possam atender efetivamente a demanda da Educação Básica, principalmente, na disciplina de Arte, tão carente de professores com formação nessa área em áreas rurais.

\section{REFERÊNCIAS}

BRASIL. Lei de Diretrizes e Bases da

Educação Nacional: Lei n. 9394/96. Brasília:

Câmara dos Deputados/Edições Câmara, 2013.

BOGDAN, R. I.; BIKLEN, E. Investigação qualitativa em educação. São Paulo: Atlas, 2010 .

DIRETRIZES CURRICULARES DO ESTÁGIO

CURRICULAR SUPERVISIONADO DO

CURSO DE EDUCAÇÃO DO CAMPO COM

HABILITAÇÃO EM ARTES E MÚSICA.

Departamento de Educação do Campo. Campus de Tocantinópolis. Universidade Federal do Tocantins, 2016.

ERICKSON, F. Qualitative methods in research on teaching. Michigan: The Institute for Research on Teaching, 1985.

GOMES, D. A.; VIZOLLI, I.; SANTOS, J. S.; STEPHANI, A. D. A construção identitária da Licenciatura em Educação do Campo na UFT: perspectivas docentes. Revista HISTEDBR On-line, Campinas, 71, p. 373-396, 2017. DOI: http://dx.doi.org/10.20396/rho.v17i71.8645405

LEI n. 11.788, de 25 de setembro de 2008.

Dispõe sobre o estágio de estudantes. Brasília: MEC, 2008.

LOPES, W. J. F.; SILVA, E. A. Base de profissionalidade do trabalho docente na Educação do Campo. Revista Brasileira de Educação do Campo, Tocantinópolis, v. 3, n. 3, set./dez., p. 810-833, 2018. DOI:

http://dx.doi.org/10.20873/uft.2525$\underline{4863.2018 v 3 \mathrm{n} 2 \mathrm{p} 810}$

MOLINA, M. Expansão das licenciaturas em Educação do Campo: desafios e potencialidades. Educar em Revista, Curitiba, n. 55, p. 145-166, 2015. DOI: https://doi.org/10.1590/0104$\underline{4060.39849}$

PARECER CNE/CEB, n. 35/2003. Dispõe sobre as normas para a organização e realização de estágio de alunos do Ensino Médio e da Educação Profissional. Brasília: MEC/CNE/CEB, 2003. 
PIMENTA, S. G. Estágio e Docência. São Paulo: Cortez, 2010.

PROJETO PEDAGÓGICO DO CURSO.

Departamento de Educação do Campo. Campus de Tocantinópolis. Universidade Federal do Tocantins, 2018.

RESOLUÇÃO n. 2, de $1^{\circ}$ de Julho de 2015. Define as Diretrizes Curriculares Nacionais para a formação inicial em nível superior. Brasília: MEC/CNE, 2015.

RESOLUÇÃO DO CONSELHO DE ENSINO, PESQUISA E EXTENSÃO (CONSEPE) $n$.

20/2012. Dispõe sobre as normas para os estágios curriculares não obrigatórios realizados por estudantes regularmente matriculados na Universidade Federal do Tocantins. Palmas: Universidade Federal do Tocantins, 2012.

SZYMANSKI, H. (Org.). A entrevista na pesquisa em educação: a prática reflexiva. Brasília: Líber Livro Editora, 2004. TRIVIÑOS, A. N. Introdução à pesquisa em Ciências Sociais: a pesquisa qualitativa em educação. São Paulo: Atlas, 1987.

VIANNA, H. M. Pesquisa em educação: a observação. Brasília: Plano Editora, 2003.

YIN, R. K. Estudo de caso: planejamento e métodos. 2. ed. Tradução de Daniel Grassi. São Paulo: Bookman Companhia Editora, 2003.
Gustavo Cunha de Araújo

Doutor em Educação pela UNESP, Marília/SP.

Professor da Universidade Federal do Tocantins.

Helena Quirino Porto Aires

Doutoranda em Educação pela UFSCar. Professora

da Universidade Federal do Tocantins. 